University of Montana

ScholarWorks at University of Montana

10-2005

\title{
Changes in Bird Abundance After Wildfire: Importance of Fire Severity and Time Since Fire
}

\author{
Kristina M. Smucker \\ Richard L. Hutto \\ University of Montana - Missoula, hutto@mso.umt.edu \\ Brian M. Steele
}

Follow this and additional works at: https://scholarworks.umt.edu/biosci_pubs

Part of the Biology Commons

Let us know how access to this document benefits you.

\author{
Recommended Citation \\ Smucker, Kristina M.; Hutto, Richard L.; and Steele, Brian M., "Changes in Bird Abundance After Wildfire: \\ Importance of Fire Severity and Time Since Fire" (2005). Biological Sciences Faculty Publications. 283. \\ https://scholarworks.umt.edu/biosci_pubs/283
}

This Article is brought to you for free and open access by the Biological Sciences at ScholarWorks at University of Montana. It has been accepted for inclusion in Biological Sciences Faculty Publications by an authorized administrator of ScholarWorks at University of Montana. For more information, please contact scholarworks@mso.umt.edu. 


\title{
CHANGES IN BIRD ABUNDANCE AFTER WILDFIRE: IMPORTANCE OF FIRE SEVERITY AND TIME SINCE FIRE
}

\author{
Kristina M. Smucker, ${ }^{1,4}$ Richard L. Hutto, ${ }^{2}$ and Brian M. Steele ${ }^{3}$ \\ ${ }^{1}$ Wildlife Biology Program, University of Montana, Missoula, Montana 59812 USA \\ ${ }^{2}$ Avian Science Center, Division of Biological Sciences, University of Montana, Missoula, Montana 59812 USA \\ ${ }^{3}$ Department of Mathematical Sciences, University of Montana, Missoula, Montana 59812 USA
}

\begin{abstract}
Fire can cause profound changes in the composition and abundance of plant and animal species, but logistics, unpredictability of weather, and inherent danger make it nearly impossible to study high-severity fire effects experimentally. We took advantage of a unique opportunity to use a before-after/control-impact (BACI) approach to analyze changes in bird assemblages after the severe fires of 2000 in the Bitterroot Valley, Montana. Observers surveyed birds using 10-minute point counts and collected vegetation data from 13 burned and 13 unburned transects for five years before fire and three years after fire. We compared changes in vegetation variables and relative bird abundance from before to after fire between the set of points that burned and the set of points that did not burn. The magnitude of change in vegetation variables from before to after fire increased with fire severity. The relative abundances of nine bird species showed significantly greater changes from before to after fire at burned points compared with unburned points. Moreover, when burned points were separated by whether they burned at low, moderate, or high severity, an additional 10 species showed significant changes in relative abundance from before to after fire at one or more severities. Overall, almost twice as many bird species increased as decreased significantly in response to fire. We also found changes in abundance between one year after and two years after fire for most species that responded to fire. Thus, species that have been termed "mixed responders" in the literature appear to be responding differently to different fire severities or different time periods since fire, rather than responding variably to the same fire conditions. These findings underscore the importance of fire severity and time since fire and imply that both factors must be considered to understand the complexities of fire effects on biological communities. Because different bird species responded positively to different fire severities, our results suggest a need to manage public lands for the maintenance of all kinds of fires, not just the low-severity, understory burns that dominate most discussions revolving around the use of fire in forest restoration.
\end{abstract}

Key words: avian communities; BACI approach; before-after comparison; bird abundance; conifer forest; fire effects; fire severity; mixed-severity fire; Northern Rocky Mountains; wildfire.

\section{INTRODUCTION}

Environmental disturbance is an important process in all ecosystems because it alters habitat structure and resource availability. Throughout western North America, wildfire is the primary recurring disturbance that has shaped floral and faunal communities (Habeck and Mutch 1973, Agee 1993, Arno and Allison-Bunnel 2002). Wildfire creates a mosaic of patch types when severity, extent, and frequency vary over time and space, and this resulting landscape heterogeneity is one of the main factors influencing species diversity (Brawn et al. 2001, Platt and Connell 2003, Turner et al. 2003). Further, studies conducted in burned forests have revealed that there are species within virtually all taxa that respond positively to fire (for reviews see

Manuscript received 31 August 2004; revised 15 March 2005; accepted 18 March 2005. Corresponding Editor: G. H. Aplet.

${ }^{4}$ Present address: Avian Science Center, Division of Biological Sciences, University of Montana, Missoula, Montana 59812 USA. E-mail: kristina.smucker@mso.umt.edu
Whelan 1995, Smith 2000), indicating that postfire habitat is valuable habitat in its own right. Indeed, bird assemblages in forests that have experienced high-severity wildfire are unique compared with those in unburned forests, and several species are even relatively restricted to burned forest conditions (Taylor and Barmore 1980, Hutto 1995, Caton 1996, Kotliar et al. 2002). In addition, a number of species that are more broadly distributed across a variety of unburned forest types are, nonetheless, detected relatively frequently in burned forests (Hutto 1995), suggesting that burned forests provide important habitat for bird species that are more eurytopic as well.

While the effects of fire on species that respond strongly to fire (i.e., species whose abundances are clearly greater in burned than in unburned areas) are consistent and unambiguous among previous studies (see review by Kotliar et al. 2002), generalizations about how fire affects the abundance of many other bird species have been elusive. For example, two studies conducted in similar forest types in Yellowstone 


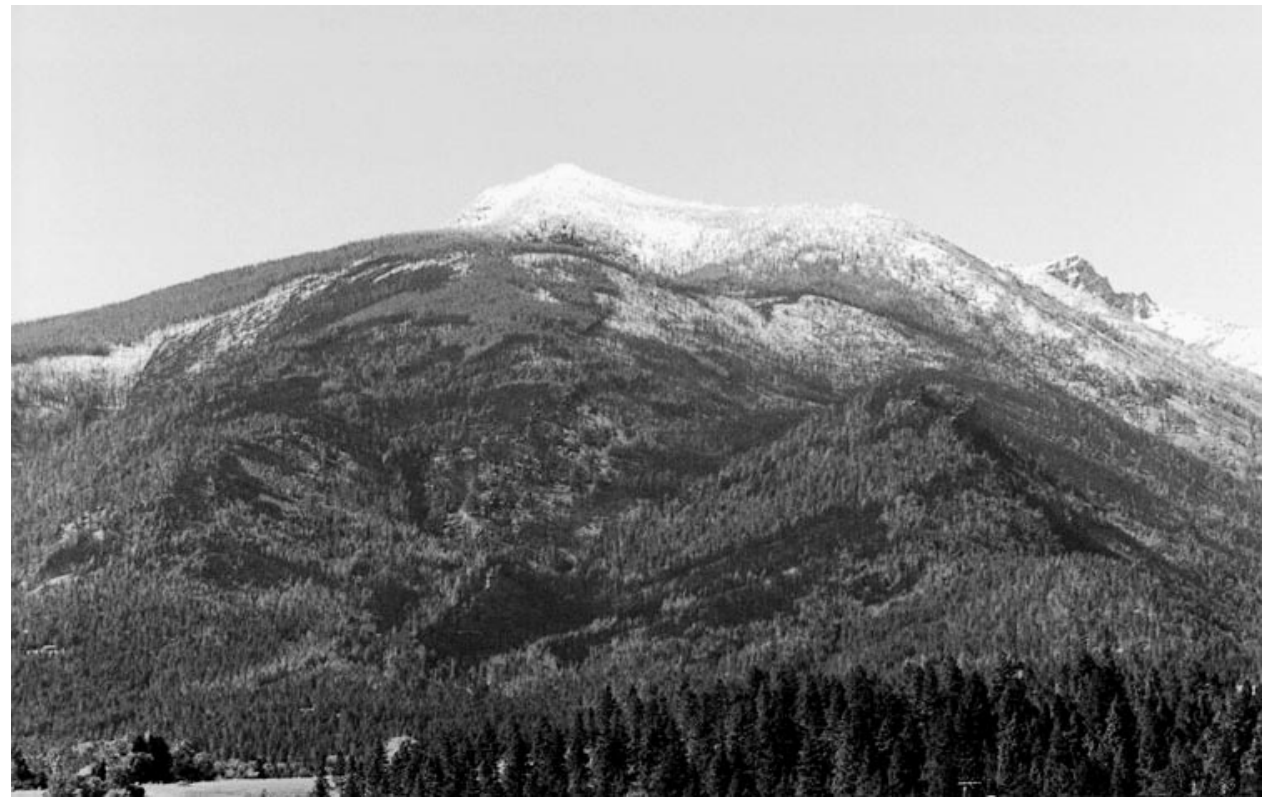

Plate 1. This photo illustrates the mixture of communities and fire severities that typify naturally occurring wildfires in most mixed-conifer forest types within the northern Rocky Mountains (USA). Because different bird species respond positively to different fire severities, our results suggest a need to manage public lands so that the full range of burned forest conditions are retained after the restorative process of fire has occurred. Photo credit: R. L. Hutto.

National Park found opposite results for Clark's Nutcracker (Nucifraga columbiana): Taylor and Barmore (1980) found the species to be more abundant in burned forest, while Pfister (1980) found the species to be more abundant in unburned forest. Similarly, several studies found American Robin (Turdus migratorius) to be more than twice as abundant in burned than in unburned plots (Bock and Lynch 1970, Taylor and Barmore 1980), whereas others found either little difference between burned and unburned plots or that the response varied among burned plots (Pfister 1980, Harris 1982, Bock and Bock 1983, Skinner 1989). In fact, a recent review of 11 studies that compared bird communities between burned and unburned forest showed that 18 species exhibit "mixed" responses to fire (Kotliar et al. 2002), that is, the same species showed some combination of positive, neutral, and negative responses when tallied across studies.

These inconsistencies across studies are difficult to reconcile unless fire effects on bird abundance vary with characteristics of individual fires (e.g., fire severity and burn matrix), site-specific factors (e.g., prefire forest structure), or time since fire (Smith 2000, Kotliar et al. 2002, Short 2003). Few previous studies have explicitly examined how variation in fire severity affects bird abundance, but there is evidence that some species decrease in abundance in forests that have experienced high-severity fire and increase in abundance at lower fire severities (Taylor and Barmore 1980, Johnson and Wauer 1996, Kotliar et al. 2002). Because most studies do not provide detailed or standardized descriptions of postfire habitat, it is often difficult to discern what the fire severity was, or whether residual patches of unburned forest remained. Thus, apparent inconsistencies in a species' response to fire could result from the fact that the authors studied forests of different types or forests that burned at different severities.

A second reason for variability in results among fire effects studies may be that most previous studies of fire effects on birds are comparative in nature, lack prefire data, and have little or no treatment replication. This is primarily because of obvious political and logistical difficulties that prohibit the study of high-severity wildfire experimentally. Unfortunately, the potential for being misled by comparative studies of fire effects is high not only because it is difficult to control for the large number of factors that differ between sites that are used for comparison, but also because such comparative studies are inadequately replicated (Whelan 1995, Turner and Dale 1998, Short 2003).

An ideal study of fire effects would use a beforeafter/control-impact (BACI; Stewart-Oaten et al. 1986) approach in which bird abundances were measured at many independently burned sites across a large area both before and after wildfire. Such a study would provide a stronger base of inference for concluding that observed changes in avian community composition and abundance were due to fire. Unfortunately, opportunities to study high-severity wildfire using a BACI approach are rare. However, the wildfires of 2000 in the Bitterroot Valley, Montana, presented an opportunity that was close to ideal when a number of point-count transects that are part of the Northern Region Landbird Monitoring Program burned at a range of fire severities. 
As a result of long-term monitoring efforts, one to five years of prefire point-count and vegetation data existed at over two dozen locations in the Bitterroot National Forest. This made it possible to conduct postfire surveys at the same points and then to compare changes in avian abundance, species composition, and vegetation structure from before to after wildfire in both burned and unburned forest patches in the same area. Here, we used a BACI approach to evaluate the effect of fire on bird abundance following a stand-replacing fire in a conifer forest. Our objectives were to determine how bird abundance changed following wildfire and to examine the relationship between changes in abundance and both fire severity and time since fire.

\section{Methods}

\section{Study area}

The study took place in the Bitterroot National Forest in west-central Montana, primarily in low-elevation ponderosa pine (Pinus ponderosa) / Douglas-fir (Pseudotsuga menziesii) communities and mid-elevation mixed-conifer and lodgepole pine (Pinus contorta) communities (see Plate 1). The shrub communities in this area are diverse and vary with elevation (which ranges from 1340 to $2440 \mathrm{~m}$ ), but dominant species throughout include common snowberry (Symphoricarpos alba), birchleaf spiraea (Spiraea betulifolia), mallow ninebark (Physocarpus malvaceus), creeping Oregon-grape (Berberis repens), and huckleberry (Vaccinium spp.). Study sites consisted of the areas surrounding a subset of permanently marked point-count transects that are part of the Northern Region Landbird Monitoring Program (information available online). ${ }^{5}$ Transects were selected in 1994 and 1995 by choosing a random starting point for each transect after stratification by USGS topographic quad (Hutto and Young 1999).

The study design was comparative and observational but included controls, repeated measures over time, and a natural intervention (James and McCulloch 1995). Because we took advantage of an unplanned wildfire and had no control over which transects burned, control and treatment plots were not selected randomly. Instead, we used all transects that burned $(n=13)$, and selected a subset of existing transects within and around the fire perimeter that did not burn $(n=13)$ to serve as controls. The unburned transects matched the range of habitat types and elevations spanned by burned transects, and the two kinds of transects were well interspersed throughout the Bitterroot National Forest (Fig. 1).

Each permanently marked transect was $3-4.5 \mathrm{~km}$ long with 10 points spaced a minimum of $250 \mathrm{~m}$ apart. Transects followed secondary and tertiary U.S. Forest Service roads and trails, and they passed through a range of management types, from recent clearcuts to

\footnotetext{
${ }^{5}\langle$ http://www.avianscience.org/research_landbird.htm $\rangle$
}

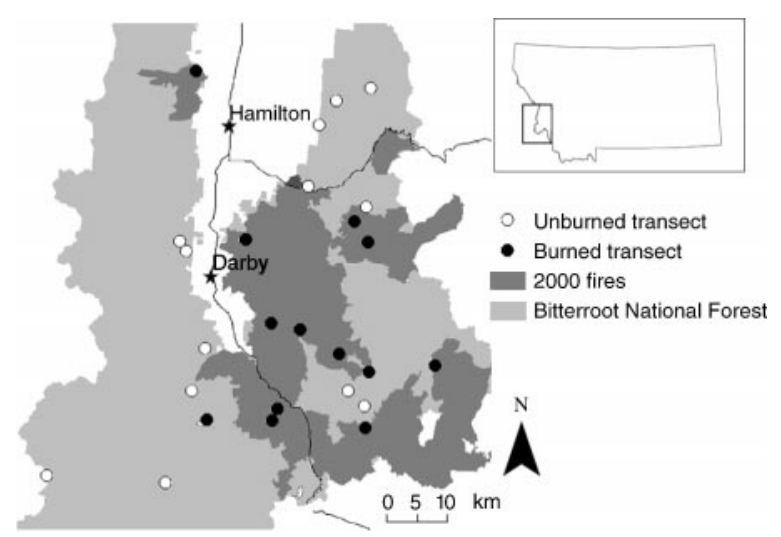

FIG. 1. The study area in the Bitterroot National Forest, Montana, USA, showing areas that burned in the wildfires of 2000 and the location of burned and unburned transects.

mature forest. To minimize the potentially confounding effects of sampling across this range of management types, all points used in this analysis contained stands of mature forest within $100 \mathrm{~m}$ of the point, and for most points (223 of 242), mature forest comprised $\geq 50 \%$ of this $100-\mathrm{m}$ radius.

\section{Fire effects}

Between 12 and 31 July 2000, dry lightning storms ignited hundreds of small fires throughout the Bitterroot National Forest. Individual fires ranged from $<40$ ha to 55000 ha, and by 6 August many of these fires had merged to form a large fire complex. Fire characteristics were highly variable across time and space, and fire behavior ranged from creeping surface fires with deep flame fronts to low-intensity fires with rapid rates of spread to sustained crown fires with flame lengths of $60-90 \mathrm{~m}$. The fires were extinguished by a combination of rainfall and active fire suppression efforts between September and October (USDA Forest Service $2000 a$ ). In all, $\sim 125000$ ha, or nearly $20 \%$ of the Bitterroot National Forest, burned at a range of fire severities, as estimated by Burned Area Emergency Rehabilitation team (BAER) assessments (USDA Forest Service 2000b). The BAER fire severity estimates are based on fire effects on soils, where a high-severity rating indicates that $>40 \%$ of the soil in a polygon exhibited features likely to increase soil runoff and erosion, moderate severity indicates $<40 \%$ of the soil has these features, and low severity indicates that duff layers are burned but intact. BAER teams classified 34500 ha as having burned at high severity, 22600 ha at moderate severity, and 67100 ha at low severity (USDA Forest Service 2000b).

As a result of the variability in fire behavior, some transects in this study were exposed to low-severity surface fires, others experienced stand-replacing events, and many experienced a combination of these extremes. For this reason, the points along the 13 transects that burned encompassed much of the range of 
fire severities and conditions that existed after this large fire event.

\section{Vegetation protocol}

The vegetation surrounding each point was assigned a vegetation cover type and one or more edge types following Northern Region Landbird Monitoring Program methods (Hutto and Young 1999). Cover type classifications were based on the dominant plant species and habitat structure (e.g., a ponderosa pine clearcut at the tall shrub stage). Two different protocols were used to collect prefire data: a "quick" vegetation protocol was conducted in most years prior to fire, and an intensive protocol was used in 1999. The vegetation variables measured according to each protocol differed primarily in that two $30 \mathrm{~m}$ radius plots were measured under the intensive protocol and a single plot was measured under the quick protocol (for details see Smucker 2003). Within a $30 \mathrm{~m}$ radius plot centered over the point we recorded the percent cover and dominant species for the following vegetation layers: canopy $(\geq 10 \mathrm{~cm}$ in diameter at breast height $[\mathrm{dbh}])$, sapling $(5-10 \mathrm{~cm}$ $\mathrm{dbh})$, seedling $(<5 \mathrm{~cm} \mathrm{dbh})$, tall shrub $(>1 \mathrm{~m})$, and low shrub $(<1 \mathrm{~m})$. Only percent cover was recorded for the grass-forb layer. We recorded the mean canopy height and the abundance of snags (i.e., standing dead trees) and downed wood categorically, where $0=$ none, $1=$ one to three snags or one to five $\operatorname{logs}$, and $2=$ greater than three snags or five logs. In a 15 m radius plot, centered within the $30 \mathrm{~m}$ radius plot, the number of small $(5-10 \mathrm{~cm} \mathrm{dbh})$, medium (10-40 cm dbh), and large ( $\geq 40 \mathrm{~cm} \mathrm{dbh}$ ) trees were tallied and recorded as live or dead.

We collected postfire vegetation data in 2001 and 2002 following the same protocol. We categorized fire severity at each point according to the percentage mortality of trees $(\geq 10 \mathrm{~cm} \mathrm{dbh})$ within $100 \mathrm{~m}$, with low severity defined as $<20 \%$ tree mortality, moderate severity defined as $20-80 \%$ mortality, and high severity defined as $>80 \%$ tree mortality. We did not include unburned patches within the larger burn, so all lowseverity points were burned to some extent (even if there was no tree mortality). We excluded data from 10 unburned points that occurred on transects that burned to ensure that all unburned points were $>400$ $\mathrm{m}$ from burned forest.

\section{Bird surveys}

Prefire bird data were collected in 1994, 1995, 1996, 1998, and 2000 from a total of 26 transects. However, not all transects were surveyed in each of these years. Eight transects were visited in all five years, 11 transects in four years, three transects in three years, two transects in two years, and two transects in a single year prior to fire. After the 2000 wildfires, 26 transects were surveyed in 2001, 25 transects in 2002, and 20 transects in 2003. We surveyed the bird community using 10-minute point counts (Hutto et al. 1986, Ralph et al. 1995), and for all birds seen or heard, we estimated the distance to the bird. Each transect was visited once between 22 May and 15 July.

Several measures were taken to promote consistency across years and among observers. Postfire counts were conducted as close as possible to the median count date from prefire years. We conducted all counts between 06:00 and 11:00 during reasonable weather conditions (i.e., low wind and no steady rain). All observers, except the 2003 observer, received intensive training in distance estimation and bird identification by sight and song. Finally, a single observer conducted all counts in a given postfire year, eliminating the potential for observer bias among fire severities.

\section{Data analyses}

In comparing relative bird abundances between burned and unburned treatments, the main potential for error was for detecting birds more readily in open, burned habitat than unburned habitat. We explored this possibility by examining detection profiles at low, moderate, and high-severity burned and unburned points to determine whether birds were detected at greater distances in burned forest. Detection profiles for the four treatments were similar within $100 \mathrm{~m}$, suggesting little difference in detectability between burned and unburned forest within this distance. Thus, only detections within $100 \mathrm{~m}$ of the point were used to calculate an index of abundance (hereafter relative abundance) for all species detected at least three times. For one species, the Olive-sided Flycatcher (Contopus cooperi), we also calculated relative abundance within an expanded detection radius $(400 \mathrm{~m})$ because this species maintains large, well-spaced territories, vocalizations are reliably detected up to $800 \mathrm{~m}$ (Altman and Sallabanks 2000), and most detections were from beyond $100 \mathrm{~m}$.

We evaluated the effects of fire on vegetation and relative bird abundance by comparing the magnitude of change (from before to after fire) that occurred at burned and unburned points. We used vegetation data collected between 1994 and 1996 to calculate a mean prefire value for each vegetation variable and data collected in 2002 as the postfire estimate. The locations of some vegetation plots changed from early to later years, so only those points $(n=182)$ at which the vegetation plots were located in the same place before and after fire were included in the vegetation analyses. To evaluate changes in relative bird abundance after wildfire, we used all points with a mature forest component $(n=242)$. Because we returned to the same points each year to collect vegetation data and to conduct point counts, annual estimates of these variables were not independent. To account for this we used preand postfire annual estimates to calculate before- and after-fire means for each point. We then calculated the difference (after-fire mean minus before-fire mean) for 
vegetation variables and relative bird abundance at each point.

In an ideal study of fire effects, a researcher might randomly select the same number of sample units for burned and unburned treatments and ensure that fire severity was uniform within a sample unit. In our study, primary sample units consisted of transects, each made up of 10 secondary sample units (points). Because we took advantage of a natural intervention, we did not control which transects burned, what the fire severity was, or whether fire severity was homogeneous among points within a transect. Thus, transect is treated as a random (rather than a fixed) factor, and the observed number of points within a transect that burned can be thought of as a realization of a random process. Analyzing these kinds of data using the typical form of a linear model and treating transect as a fixed factor results in a scope of inference that applies only to the sampled transects. However, this limitation is avoided by using a linear mixed model in which transect is treated as a random factor; this kind of analysis allows for inferences to be applied to the entire population from which samples (in this case points) were drawn (Steele and Hogg 2003). Additionally, the linear mixed model accommodates observations that are not independent. In our case, observations made at different points on the same transect were not viewed as independent because observations within a transect could be more alike than observations from different transects. The linear mixed model accommodates this source of dependency by treating transect as a random factor.

For this study, a useful linear mixed model that identifies transect as a random factor and burn status (burned or unburned) as a fixed factor is

$$
Y_{i j}=\alpha_{0}+\alpha_{1} x_{i j}+b_{i}+\varepsilon_{i j}
$$

where $Y_{i j}$ is an observation on the response variable (either a vegetation variable or relative bird abundance) obtained at the $i$ th transect, $i=1, \ldots, q$ and the $j$ th point, $j=1, \ldots, n_{i}$ within the $i$ th transect. The variable $x_{i j}$ is a $0-1$ variable identifying the burn status of the $j$ th point on the $i$ th transect. The parameter $\alpha_{0}$ is the model intercept, and $\alpha_{1}$ is the burn status effect coefficient. Differences among transects are accounted for through the transect random effects $b_{i}, i=1, \ldots, q$. Transect effects are assumed to be independent and normally distributed with a mean of 0 and a variance $\gamma$. Residual variation is accounted for by the random errors $\varepsilon_{i j}$, which are also assumed independent and normally distributed with a mean 0 and variance $\sigma^{2}$.

The parameters of the linear mixed model are the fixed effects parameters $\alpha_{0}$ and $\alpha_{1}$ and the variance components $\gamma$ and $\sigma^{2}$. These parameters were estimated using the maximum likelihood method. We first tested the null hypothesis that the amount of change, from before to after fire, for a given response variable (vegetation variables or relative bird abundance) was the same at burned and unburned points, i.e., $\alpha_{1}=0$ vs. the alternative $\alpha_{1} \neq 0$. The test was carried out using a type III sums-of-squares $F$ test. We then ran a second analysis, again using a linear mixed model in which transect was treated as a random effect and fire severity was entered as the fixed factor, to test for differences in the amount of change in the response variable among four treatment levels (unburned, low, moderate, and high severity).

We examined changes in vegetation between one and two years after fire at all points where vegetation data were collected in both years. The linear mixed model was used as above to determine whether the amount of change in vegetation cover from one year after to two years after fire differed among fire severities. All linear mixed model analyses were carried out using SPSS 11.5. We present computed $P$ values accompanying each statistical test, but in our discussion of results we refer to tests as significant when $P<0.1$ because we want to draw attention to any species that shows some evidence of a response to fire.

We looked for changes in relative bird abundance among postfire years qualitatively because data became too sparse to evaluate statistically when broken down by both fire severity and year. We did so by inspecting line graphs of relative bird abundance across postfire years and by noting whether relative abundance of a species changed between the first and third year after fire. In addition, because a single observer conducted all counts for the first two years after fire, which eliminates the potential for observer effects between these years, we also noted species for which relative abundance showed a twofold increase or decrease from one year after fire to two years after fire.

\section{RESULTS}

\section{Vegetation change}

After wildfire, the vegetation surrounding burned points experienced significantly greater change than the vegetation surrounding unburned points in all measures except tall shrub cover, grass-forb cover, and number of large live trees (Table 1). Specifically, the percent cover of all vegetation layers and numbers of live trees decreased, while snag abundance increased. Further, points that burned at high severity had greater decreases in percent cover for most vegetation layers and for numbers of live small-dbh and medium-dbh trees, than points that burned at moderate or low severity (Table 1). All vegetation layers also showed additional (though mostly nonsignificant) change from one year after to two years after fire (Table 2).

\section{Patterns of change in bird abundance}

Across the eight-year period, we detected 11977 birds representing 90 different species within 100 m of the survey points $(n=242)$. Sixty-nine species were detected three or more times across all years of the 
TABLE 1. Before-to-after fire differences (mean $\pm \mathrm{SE}$ ) in vegetation characteristics surrounding points that were unburned or that burned at low ( $<20 \%$ tree mortality), moderate (20-80\% tree mortality), or high ( $>80 \%$ tree mortality) severity.

\begin{tabular}{|c|c|c|c|c|c|c|c|}
\hline Vegetation variable & $\begin{array}{c}\text { Unburned } \\
(n=94)\end{array}$ & $\begin{array}{c}\text { Low } \\
(n=33)\end{array}$ & $\begin{array}{l}\text { Moderate } \\
(n=27)\end{array}$ & $\begin{array}{c}\text { High } \\
(n=28)\end{array}$ & df & $F \dagger$ & $P$ \\
\hline \multicolumn{8}{|l|}{ Percent cover } \\
\hline Canopy & $2.6 \pm 1.7$ & $-1.7 \pm 2.2$ & $-11.6 \pm 2.3$ & $-15.1 \pm 2.4$ & $3,54.5$ & 16.4 & $<0.001$ \\
\hline Sapling & $-0.7 \pm 1.4$ & $-2.8 \pm 1.8$ & $-3.7 \pm 2.0$ & $-8.0 \pm 2.0$ & $3,52.5$ & 3.3 & 0.027 \\
\hline Seedling & $3.2 \pm 1.1$ & $-0.8 \pm 1.6$ & $-1.1 \pm 1.8$ & $-6.2 \pm 1.8$ & $3,45.6$ & 6.6 & 0.001 \\
\hline Tall shrub & $3.0 \pm 1.7$ & $0.9 \pm 2.2$ & $-1.2 \pm 2.4$ & $-1.5 \pm 2.4$ & $3,50.2$ & 1.0 & 0.411 \\
\hline Low shrub & $7.2 \pm 2.7$ & $1.9 \pm 3.3$ & $2.1 \pm 3.5$ & $-6.0 \pm 3.5$ & $3,50.3$ & 3.5 & 0.021 \\
\hline Grass-forb & $-12.9 \pm 3.6$ & $-0.4 \pm 4.3$ & $-3.6 \pm 4.5$ & $-1.5 \pm 4.6$ & $3,52.3$ & 1.8 & 0.156 \\
\hline Index of snag presence $\neq$ & $0.1 \pm 0.1$ & $0.7 \pm 0.1$ & $0.8 \pm 0.2$ & $1.0 \pm 0.2$ & $3,56.4$ & 6.9 & $<0.001$ \\
\hline Index of downed log presence $\S$ & $0.1 \pm 0.1$ & $-0.4 \pm 0.1$ & $-0.1 \pm 0.1$ & $-0.3 \pm 0.1$ & $3,52.6$ & 3.4 & 0.024 \\
\hline Number of large live trees & $-0.2 \pm 0.2$ & $-0.2 \pm 0.2$ & $-0.6 \pm 0.2$ & $-0.6 \pm 0.2$ & $3,50.1$ & 1.5 & 0.214 \\
\hline Number of medium live trees & $2.4 \pm 1.2$ & $-1.5 \pm 1.5$ & $-4.5 \pm 1.6$ & $-11.0 \pm 1.6$ & $3,56.9$ & 17.2 & $<0.001$ \\
\hline Number of small live trees & $2.2 \pm 1.2$ & $-2.1 \pm 1.7$ & $-2.7 \pm 1.8$ & $-7.5 \pm 1.8$ & $3,59.6$ & 6.5 & 0.001 \\
\hline
\end{tabular}

$\dagger F$ test of significance uses the type III sums-of-squares obtained from a linear mixed model.

\$ Index of snag presence: 0 , none; $1,1-3$ snags; $2,>3$ snags.

$\S$ Index of downed log presence: 0 , none; $1,1-5 \operatorname{logs} ; 2,>5 \operatorname{logs}$.

study and of these, one species (Black-backed Woodpecker) was detected at burned points only, while nine species were detected at unburned points only (Table 3). By simply asking whether species were affected by fire independent of fire severity or time since fire, nine of the 40 species that were detected frequently enough to include in a statistical analysis showed significant changes in relative abundance from before to after fire on burned relative to control points (Table 3). Four of these species (Townsend's Solitaire [Myadestes townsendi], Dark-eyed Junco [Junco hyemalis], Lazuli Bunting [Passerina amoena], and Cassin's Finch [Carpodacus cassinii]) increased in relative abundance after fire, and five species (Cassin's Vireo [Vireo cassinii], Golden-crowned Kinglet [Regulus satrapa], Rubycrowned Kinglet [(Regulus calendula)], Swainson's Thrush [Catharus ustulatus], and Yellow-rumped Warbler [Dendroica coronata]) decreased in relative abundance after fire.

By placing burned points into categories that correspond with whether they burned at low, moderate, or high severity, we discovered significant changes in relative abundance from before to after fire at one or more severities for an additional 9 species (Table 4). In addition, the use of an expanded detection radius of 400 $\mathrm{m}$ for the Olive-sided Flycatcher revealed that it was significantly more abundant after fire at moderate and high severity points (unburned, $3.9 \pm 4.5$ individuals low, $2.7 \pm 5.4$; moderate, $12.8 \pm 6.1$; high, $20.5 \pm$ 6.1 ; mean \pm sE, $F=2.8$, df $=3,58.5, P=0.048$ ). Thus, after accounting for fire severity, 12 species were significantly more abundant after fire and seven species were significantly less abundant after fire at one or more severities. Four additional species (American Threetoed Woodpecker [Picoides dorsalis], Black-backed Woodpecker, Western Wood-Pewee [Contopus sordidulus], and House Wren [Troglodytes aedon]) have been reported previously (Kotliar et al. 2002) to be more abundant in burned than unburned forest, but they were not detected in sufficient numbers to conduct statistical analyses. Nonetheless, an examination of the number of transects and points on which these species were detected before and after fire reveals that all four species were detected more frequently after fire (Table $5)$. Thus, a total of 16 species were likely to have responded positively to at least one level of fire severity.

Of the 19 species whose relative abundance changed significantly in response to fire, only three (Goldencrowned Kinglet, Lazuli Bunting, and Cassin's Finch) changed to a similar extent across all fire severities. In most cases, species increased or decreased significantly in response to fire at only one fire severity, and each generally followed one of four basic patterns of change, as illustrated in Fig. 2. Five species (Northern Flicker [Colaptes auratus], Hairy Woodpecker [Picoides villosus], Olive-sided Flycatcher, Mountain Bluebird [Sialia currucoides], and Townsend's Solitaire) increased significantly at points that burned at high severity (pattern exemplified in Fig. 2A). Three species (American Robin, Chipping Sparrow [Spizella passerina], and Dark-eyed Junco) increased significantly only at points that burned at moderate severity (pattern exemplified in Fig. 2B). Two species (Hermit Thrush [ $\mathrm{Ca}$ tharus guttatus] and Western Tanager [Piranga ludoviciana]) actually decreased at points that burned at high severity while increasing in relative abundance at points that burned at low severity (pattern exemplified in Fig. 2C). Finally, six species (Dusky Flycatcher [Empidonax oberholseri], Cassin's Vireo, Ruby-crowned Kinglet, Swainson's Thrush, Townsend's Warbler [Dendroica townsendi], and Yellow-rumped Warbler) decreased significantly at more severely burned points, and most of these species showed incremental decreases in relative abundance as fire severity increased (pattern exemplified in Fig. 2D). Many of the latter species, which decreased at points that burned at high severity, also showed a modest to significant increase in relative abundance at unburned points (Fig. 2D). 
TABLE 2. Differences (mean \pm SE) in percent cover between one and two years postfire within six vegetation layers at points that were unburned or that burned at low, moderate, or high severity.

\begin{tabular}{lcccccc}
\hline \hline $\begin{array}{l}\text { Vegetation cover } \\
\text { variable }\end{array}$ & $\begin{array}{c}\text { Unburned } \\
(n=48)\end{array}$ & $\begin{array}{c}\text { Low } \\
(n=48)\end{array}$ & $\begin{array}{c}\text { Moderate } \\
(n=32)\end{array}$ & $\begin{array}{c}\text { High } \\
(n=36)\end{array}$ & $\mathrm{df}$ \\
\hline Canopy & $-6.1 \pm 2.3$ & $-8.4 \pm 2.1$ & $-7.3 \pm 2.4$ & $-3.3+2.4$ & $3,40.5$ & 1.2 \\
Sapling & $0.2 \pm 1.2$ & $-1.8 \pm 1.1$ & $-1.8 \pm 1.2$ & $-1.3 \pm 1.2$ & $3,43.9$ & 0.6 \\
Seedling & $1.3 \pm 1.5$ & $-0.7 \pm 1.3$ & $-0.2 \pm 1.5$ & $-0.2 \pm 1.5$ & $3,48.5$ & 0.3 \\
Tall shrub & $1.4 \pm 1.9$ & $-1.1 \pm 1.7$ & $-0.8 \pm 1.8$ & $-1.1 \pm 1.9$ & $3,33.8$ & 0.4 \\
Low shrub & $-1.1 \pm 2.7$ & $2.5 \pm 2.4$ & $4.1 \pm 2.7$ & $1.9 \pm 2.7$ & $3,44.1$ & 0.6 \\
Grass-forb & $-4.1 \pm 3.8$ & $1.2 \pm 3.4$ & $2.6 \pm 3.9$ & $\mathbf{1 2 . 4} \pm \mathbf{3 . 9}$ & $3,52.6$ & 3.6 \\
\hline
\end{tabular}

Note: Only grass-forb cover increased significantly (highlighted in bold) in the second year after fire at points that burned at high severity compared to unburned points.

$\dagger F$ test of significance uses the type III sums-of-squares obtained from a linear mixed model.

Despite considerable yearly variation in relative abundance, many species revealed incremental changes in relative abundance from the first postfire year to subsequent postfire years. Hairy Woodpecker and Lazuli Bunting are two examples of this pattern; both species increased in relative abundance at burned points in each of the first three years after fire (Fig. 3). Indeed, many species that increased in relative abundance from before fire to after fire at one or more severities were more than twice as abundant the second year after fire as the first year after fire (Table 4). Northern Flicker (Fig. 3) was unusual among species that increased after fire because it was not detected regularly until three years after fire. Bird species that decreased in response to fire at one or more severities showed the same pattern of change: most were less than half as abundant in the second as in the first year after fire (Table 4). For example, Western Tanager showed greater decreases in relative abundance two years after fire than one year after fire at points that burned at moderate and high severity (Fig. 3). For both increasers and decreasers, the magnitude of change in relative abundance between the first two years after fire was generally greater at points that burned at high or moderate severity than at points that were unburned or that burned at low severity.

\section{Discussion}

\section{Changes in vegetation}

Postfire vegetation measurements were collected primarily to verify that our rapid assessment of fire severity was meaningful. Fire severity classifications were based on percentage tree mortality, so the inverse relationship between fire severity and two vegetation variables (percent canopy cover and live tree counts) was expected. Less expected was the fact that our simple index of fire severity also tracked the magnitude of change in other vegetation layers quite well. Most vegetation layers experienced incremental decreases in cover as fire severity increased, but these decreases were generally significant only at high severity.

There was a delay in tree mortality, particularly at points classified as moderate and low severity, as evidenced by continued decreases in percent cover for canopy, sapling, and seedling layers in the second year following wildfire. Both low shrub and grass-forb cover increased from the first to the second year after fire, indicating rapid regrowth in these vegetation layers. These findings reinforce the idea that habitat structure and food resources for birds and other wildlife change rapidly within the first few years following wildfire (Brown and Smith 2000).

\section{Changes in relative bird abundance}

The BACI approach we used to analyze changes in relative bird abundance from before to after fire provides a basis for attributing the observed changes to fire. The list of species that were detected more frequently after high-severity wildfire using this approach is remarkably similar to the list compiled from a review of comparative studies of bird communities in burned and unburned forest (Kotliar et al. 2002). In their review of 11 studies that compared bird abundance in burned and unburned forest, nine species were typically more abundant in burned forest. Of these nine species, one (Tree Swallow, Tachycineta bicolor) was too rarely detected for inclusion in our analysis, but each of the other eight species (Hairy Woodpecker, Northern Flicker, Olive-sided Flycatcher, Mountain Bluebird, American Three-toed Woodpecker, Black-backed Woodpecker, Western Wood-Pewee, and House Wren) was detected relatively more frequently on burned points after fire. Such close agreement between our study and comparative studies that lack prefire data suggests that postfire comparisons of burned and unburned forest have been helpful in uncovering those species that respond strongly to stand-replacement fires. In fact, metaanalyses of the results from independent, comparative studies are likely to be the primary avenue for uncovering fire effects because we are unlikely to be able to conduct actual replicated experiments involving severe fires (Hargrove and Pickering 1992, Whelan 1995, Andersen et al. 1998, van Mantgem et al. 2001). For this reason, the similarity of results based on the BACI approach that we used and results derived from comparative studies lacking prefire data is reassuring.

Because of their infrequent occurrence, we were unable to attach a level of statistical significance to the 
TABLE 3. Relative abundance (mean number of birds detected within $100 \mathrm{~m}$ per point $\times 100 \pm \mathrm{SE}$ ) for 69 species that were detected at least three times across all years of the study at burned and unburned points.

\begin{tabular}{|c|c|c|c|c|c|}
\hline \multirow[b]{2}{*}{ Species $\dagger$} & \multicolumn{2}{|c|}{ Unburned points $(n=120)$} & \multicolumn{2}{|c|}{ Burned points $(n=122)$} & \multirow[b]{2}{*}{ Response\| } \\
\hline & Before fire $\ddagger$ & After fire $\$$ & Before fire $\ddagger$ & After fire & \\
\hline Red-tailed Hawk, Buteo jamaicensis & $0.3 \pm 0.2$ & $1.1 \pm 0.5$ & $0.6 \pm 0.4$ & $1.4 \pm 0.7$ & \\
\hline Ruffed Grouse, Bonasa umbellus & $1.2 \pm 0.5$ & $1.9 \pm 0.9$ & $3.1 \pm 1.0$ & $1.6 \pm 0.7$ & \\
\hline Blue Grouse, Dendragapus obscurus & $0.6 \pm 0.4$ & $0.3 \pm 0.3$ & $0.0 \pm 0.0$ & $0.3 \pm 0.3$ & \\
\hline Spotted Sandpiper, Actitus macularia & $0.0 \pm 0.0$ & $0.0 \pm 0.0$ & $0.0 \pm 0.0$ & $3.7 \pm 1.8$ & \\
\hline Mourning Dove, Zenaida macroura & $0.2 \pm 0.2$ & $0.8 \pm 0.5$ & $0.2 \pm 0.2$ & $0.3 \pm 0.3$ & \\
\hline Calliope Hummingbird, Stellula calliope & $2.9 \pm 1.3$ & $6.1 \pm 1.9$ & $0.0 \pm 0.0$ & $2.5 \pm 0.8$ & IE \\
\hline Rufous Hummingbird, Selasphorus rufus & $1.5 \pm 0.9$ & $1.1 \pm 0.5$ & $0.0 \pm 0.0$ & $0.0 \pm 0.0$ & \\
\hline Northern Flicker, Colaptes auratus & $5.9 \pm 1.1$ & $2.8 \pm 0.9$ & $8.1 \pm 2.1$ & $9.4 \pm 1.7$ & IE \\
\hline Williamson's Sapsucker, Sphyrapicus thyroideus & $4.7 \pm 1.5$ & $3.2 \pm 1.1$ & $6.6 \pm 1.6$ & $3.6 \pm 1.3$ & IE \\
\hline Red-naped Sapsucker, Sphyrapicus ruber & $0.8 \pm 0.5$ & $1.7 \pm 0.9$ & $0.9 \pm 0.5$ & $0.5 \pm 0.4$ & \\
\hline Downy Woodpecker, Picoides pubescens & $0.2 \pm 0.2$ & $0.6 \pm 0.4$ & $0.0 \pm 0.0$ & $0.0 \pm 0.0$ & \\
\hline Hairy Woodpecker, Picoides villosus & $3.0 \pm 0.7$ & $7.1 \pm 1.6$ & $3.9 \pm 1.1$ & $15.2 \pm 2.2$ & IE \\
\hline Three-toed Woodpecker, Picoides tridactylus & $0.3 \pm 0.3$ & $0.0 \pm 0.0$ & $0.4 \pm 0.4$ & $3.6 \pm 1.5$ & \\
\hline Black-backed Woodpecker, Picoides arcticus & $0.0 \pm 0.0$ & $0.0 \pm 0.0$ & $0.0 \pm 0.0$ & $0.8 \pm 0.5$ & \\
\hline Pileated Woodpecker, Dryocopus pileatus & $2.9 \pm 0.7$ & $0.8 \pm 0.5$ & $0.6 \pm 0.4$ & $0.0 \pm 0.0$ & \\
\hline Olive-sided Flycatcher, Contopus cooperi & $2.9 \pm 1.0$ & $1.7 \pm 1.0$ & $5.4 \pm 1.3$ & $5.1 \pm 1.7$ & IE \\
\hline Western Wood-Pewee, Contopus sordidulus & $1.2 \pm 0.7$ & $0.0 \pm 0.0$ & $0.0 \pm 0.0$ & $2.9 \pm 1.2$ & \\
\hline Willow Flycatcher, Empidonax traillii & $0.0 \pm 0.0$ & $0.0 \pm 0.0$ & $1.0 \pm 0.8$ & $2.0 \pm 1.4$ & \\
\hline Hammond's Flycatcher, Empidonax hammondii & $4.0 \pm 1.1$ & $14.7 \pm 3.2$ & $0.5 \pm 0.3$ & $4.4 \pm 1.3$ & IE \\
\hline Dusky Flycatcher, Empidonax oberholseri & $17.2 \pm 3.2$ & $26.5 \pm 4.9$ & $8.0 \pm 2.2$ & $10.4 \pm 2.5$ & IE \\
\hline Cassin's Vireo, Vireo cassinii & $11.2 \pm 2.0$ & $14.2 \pm 2.2$ & $7.7 \pm 1.8$ & $3.0 \pm 1.0$ & $\mathbf{D}^{*}$ \\
\hline Warbling Vireo, Vireo gilvus & $24.2 \pm 3.8$ & $26.7 \pm 4.5$ & $15.3 \pm 3.2$ & $8.6 \pm 2.4$ & IE \\
\hline Steller's Jay, Cyanocitta stelleri $\llbracket$ & $3.4 \pm 1.0$ & $2.5 \pm 1.2$ & $6.6 \pm 1.5$ & $5.9 \pm 1.7$ & \\
\hline Gray Jay, Perisoreus canadensis $\llbracket$ & $9.8 \pm 2.2$ & $8.1 \pm 2.1$ & $12.4 \pm 2.7$ & $4.2 \pm 1.5$ & \\
\hline Clark's Nutcracker, Nucifraga columbiana & $11.0 \pm 2.4$ & $5.0 \pm 1.4$ & $11.1 \pm 2.8$ & $5.1 \pm 1.6$ & IE \\
\hline Common Raven, Corvus corax & $1.3 \pm 0.6$ & $0.8 \pm 0.5$ & $1.2 \pm 0.6$ & $0.5 \pm 0.4$ & \\
\hline Violet-green Swallow, Tachycineta thalassina & $0.0 \pm 0.0$ & $1.7 \pm 1.2$ & $0.0 \pm 0.0$ & $0.0 \pm 0.0$ & \\
\hline Black-capped Chickadee, Poecile atricapillus & $4.3 \pm 1.4$ & $5.0 \pm 1.3$ & $0.4 \pm 0.3$ & $2.5 \pm 1.1$ & IE \\
\hline Mountain Chickadee, Poecile gambeli & $30.9 \pm 3.2$ & $61.4 \pm 5.6$ & $28.3 \pm 3.0$ & $42.8 \pm 4.6$ & IE \\
\hline Brown Creeper, Certhia americana & $2.2 \pm 1.0$ & $5.3 \pm 1.4$ & $0.7 \pm 0.4$ & $7.7 \pm 1.7$ & IE \\
\hline Red-breasted Nuthatch, Sitta canadensis & $51.0 \pm 4.2$ & $49.7 \pm 4.8$ & $44.0 \pm 3.8$ & $38.3 \pm 3.9$ & IE \\
\hline White-breasted Nuthatch, Sitta carolinensis & $1.4 \pm 0.7$ & $0.6 \pm 0.4$ & $0.3 \pm 0.3$ & $1.1 \pm 0.7$ & \\
\hline House Wren, Troglodytes aedon & $0.2 \pm 0.2$ & $0.0 \pm 0.0$ & $0.5 \pm 0.3$ & $3.6 \pm 1.2$ & \\
\hline Winter Wren, Troglodytes troglodytes & $3.8 \pm 1.5$ & $5.7 \pm 1.9$ & $3.3 \pm 1.0$ & $1.8 \pm 0.9$ & IE \\
\hline Rock Wren, Salpinctes obsoletus & $0.9 \pm 0.4$ & $0.3 \pm 0.3$ & $0.0 \pm 0.0$ & $1.4 \pm 0.6$ & \\
\hline Marsh Wren, Cistothorus palustris & $0.0 \pm 0.0$ & $0.0 \pm 0.0$ & $0.0 \pm 0.0$ & $1.2 \pm 0.9$ & \\
\hline Golden-crowned Kinglet, Regulus satrapa & $13.6 \pm 2.5$ & $22.4 \pm 3.7$ & $16.0 \pm 2.9$ & $5.7 \pm 1.6$ & $\mathbf{D} * *$ \\
\hline Ruby-crowned Kinglet, Regulus calendula & $29.4 \pm 3.1$ & $57.9 \pm 4.7$ & $42.3 \pm 4.4$ & $32.2 \pm 4.1$ & $\mathbf{D} * *$ \\
\hline Mountain Bluebird, Sialia currucoides & $2.0 \pm 0.8$ & $1.1 \pm 0.9$ & $3.2 \pm 1.2$ & $8.9 \pm 2.0$ & IE \\
\hline Townsend's Solitaire, Myadestes townsendi & $17.3 \pm 2.5$ & $8.5 \pm 1.6$ & $13.6 \pm 1.9$ & $14.8 \pm 2.5$ & $\mathbf{I}^{*}$ \\
\hline Swainson's Thrush, Catharus ustulatus & $14.4 \pm 2.5$ & $20.6 \pm 3.7$ & $11.7 \pm 2.0$ & $5.9 \pm 1.3$ & $\mathbf{D}^{*}$ \\
\hline Hermit Thrush, Catharus guttatus & $12.1 \pm 2.1$ & $8.6 \pm 1.9$ & $10.5 \pm 2.0$ & $9.3 \pm 1.9$ & IE \\
\hline Varied Thrush, Ixoreus naevius & $1.5 \pm 0.9$ & $1.5 \pm 1.0$ & $0.8 \pm 0.4$ & $0.0 \pm 0.0$ & \\
\hline American Robin, Turdus migratorius & $14.5 \pm 2.5$ & $15.1 \pm 2.7$ & $21.2 \pm 3.2$ & $26.8 \pm 4.2$ & IE \\
\hline Cedar Waxwing, Bombycilla cedrorum & $0.4 \pm 0.3$ & $0.3 \pm 0.3$ & $0.0 \pm 0.0$ & $0.0 \pm 0.0$ & \\
\hline Orange-crowned Warbler, Vermivora celata $\mathbb{\|}$ & $11.3 \pm 2.2$ & $13.6 \pm 2.4$ & $3.8 \pm 1.1$ & $4.9 \pm 1.4$ & \\
\hline Nashville Warbler, Vermivora ruficapilla & $0.2 \pm 0.2$ & $0.0 \pm 0.0$ & $0.3 \pm 0.3$ & $0.0 \pm 0.0$ & \\
\hline Yellow-rumped Warbler, Dendroica coronata & $28.0 \pm 5.4$ & $37.9 \pm 6.1$ & $18.1 \pm 3.4$ & $17.1 \pm 4.1$ & $\mathbf{D}^{*}$ \\
\hline Townsend's Warbler, Dendroica towsendi & $65.5 \pm 4.2$ & $93.9 \pm 6.2$ & $60.3 \pm 4.6$ & $63.7 \pm 4.4$ & IE \\
\hline Yellow Warbler, Dendroica petechia & $0.2 \pm 0.2$ & $0.0 \pm 0.0$ & $0.2 \pm 0.2$ & $0.4 \pm 0.4$ & \\
\hline MacGillivray's Warbler, Oporornis agilis & $16.9 \pm 2.6$ & $19.2 \pm 3.0$ & $25.2 \pm 4.0$ & $19.1 \pm 3.5$ & IE \\
\hline Wilson's Warbler, Wilsonia pusilla & $2.0 \pm 1.0$ & $0.3 \pm 0.3$ & $1.8 \pm 0.8$ & $0.0 \pm 0.0$ & \\
\hline Northern Waterthrush, Seiurus noveboracensis & $0.2 \pm 0.2$ & $0.0 \pm 0.0$ & $1.0 \pm 0.6$ & $0.4 \pm 0.4$ & \\
\hline Common Yellowthroat, Geothlypis trichas & $0.4 \pm 0.3$ & $0.6 \pm 0.6$ & $1.4 \pm 0.8$ & $1.6 \pm 0.8$ & \\
\hline Western Tanager, Piranga ludoviciana & $52.1 \pm 4.2$ & $54.4 \pm 4.3$ & $43.6 \pm 3.6$ & $52.0 \pm 4.7$ & IE \\
\hline Chipping Sparrow, Spizella passerina & $52.2 \pm 4.7$ & $71.9 \pm 5.8$ & $56.7 \pm 5.6$ & $98.1 \pm 8.0$ & IE \\
\hline Fox Sparrow, Passerella iliaca & $0.0 \pm 0.0$ & $0.6 \pm 0.4$ & $2.7 \pm 0.9$ & $0.8 \pm 0.6$ & \\
\hline Lincoln's Sparrow, Melospiza lincolnii & $0.2 \pm 0.2$ & $0.6 \pm 0.6$ & $4.6 \pm 1.7$ & $3.0 \pm 1.6$ & \\
\hline Song Sparrow, Melospiza melodia & $0.2 \pm 0.2$ & $0.3 \pm 0.3$ & $2.0 \pm 1.0$ & $3.6 \pm 1.5$ & \\
\hline White-crowned Sparrow, Zonotrichia leucophrys & $1.6 \pm 0.8$ & $0.0 \pm 0.0$ & $1.0 \pm 0.6$ & $0.3 \pm 0.3$ & \\
\hline Dark-eyed Junco, Junco hyemalis & $92.2 \pm 5.4$ & $92.2 \pm 6.3$ & $86.6 \pm 6.4$ & $116.8 \pm 6.8$ & I\# \\
\hline Black-headed Grosbeak, Pheucticus melanocephalus & $1.1 \pm 0.6$ & $1.1 \pm 0.5$ & $1.2 \pm 0.6$ & $0.0 \pm 0.0$ & \\
\hline Lazuli Bunting, Passerina amoena & $1.7 \pm 0.7$ & $11.4 \pm 2.9$ & $2.2 \pm 1.0$ & $33.1 \pm 4.5$ & I\# \\
\hline Brown-headed Cowbird, Molothrus ater & $10.0 \pm 2.0$ & $9.2 \pm 2.3$ & $8.9 \pm 2.0$ & $7.5 \pm 2.0$ & IE \\
\hline Cassin's Finch, Carpodacus cassinii & $3.4 \pm 0.8$ & $2.2 \pm 0.9$ & $2.0 \pm 1.0$ & $7.1 \pm 1.9$ & I\# \\
\hline Red Crossbill, Loxia curvirostra & $11.4 \pm 3.2$ & $3.8 \pm 1.6$ & $20.5 \pm 14.9$ & $9.8 \pm 4.2$ & \\
\hline Pine Grosbeak, Pinicola enucleator & $0.5 \pm 0.3$ & $1.8 \pm 0.7$ & $1.2 \pm 0.7$ & $3.7 \pm 1.5$ & \\
\hline Pine Siskin, Carduelis pinus & $33.9 \pm 4.2$ & $26.7 \pm 6.0$ & $36.1 \pm 7.4$ & $49.5 \pm 10.8$ & IE \\
\hline Evening Grosbeak, Coccothraustes vespertinus & $2.3 \pm 1.0$ & $0.6 \pm 0.4$ & $2.0 \pm 1.0$ & $0.5 \pm 0.5$ & \\
\hline
\end{tabular}


changes in relative abundance for several species (e.g., Black-backed Woodpecker, American Three-toed Woodpecker, House Wren) that have been shown in other studies to be relatively common in, and in the case of the Black-backed Woodpecker even relatively restricted to, postfire conditions (Hutto 1995, Murphy and Lehnhausen 1998, Saab and Dudley 1998, Hoyt and Hannon 2002). Nevertheless, these species were detected more commonly after fire on burned points only. Comparative studies that employ intensive sampling methods (e.g., area searches, playback surveys, or nest monitoring) will be necessary to study postfire specialist species such as these, which occur in low densities.

\section{The importance of fire severity}

Our results were particularly noteworthy in that they revealed significant increases in the postfire relative abundances of 10 additional species when we broke the data down by fire severity (Table 4). Eight of these species had been designated as "mixed" responders by Kotliar et al. (2002) in their synthesis of results from previous studies. Most importantly, our results suggest that these bird species do not have mixed responses to fire, but that their response depends on fire severity, time since fire, or both. For example, both Hermit Thrush and Western Tanager decreased in relative abundance at high-severity points, yet they increased in relative abundance at low-severity points. Thus, analyses in which comparisons are made only between burned and unburned forest, when fire severity is actually heterogeneous, would miss this positive response to low-severity fire because it is balanced by a negative response to high severity fire. In our study, increases by both species at low-severity points were consistent across all three postfire years, which further suggests this is a real response to fire. A decrease in abundance at high-severity points is not surprising, because both species nest in the foliage of live trees, and one (Western Tanager) is a foliage gleaner (Ehrlich et al. 1988). Thus, a high-severity fire would be expected to de- crease habitat suitability relative to a low-severity fire. Indeed, studies conducted in forests that have experienced high-severity wildfire generally report higher abundance in unburned forest for Hermit Thrush and either no response or mixed results for Western Tanager (Kotliar et al. 2002). A few previous studies (e.g., Taylor and Barmore 1980, Bock and Bock 1983) have provided evidence of a positive response to lower fire severities, but other studies conducted after low-severity fires have found an inconsistent response for Western Tanager, with relative abundance increasing in some replicates and decreasing in others (Granholm 1982). For Hermit Thrush, Granholm (1982) found that relative abundance decreased on burned plots after lowseverity fire, but Schulte and Niemi (1998) found that this species was more abundant on burned sites than logged sites. In our study, fire severity is extremely important in explaining changes in postfire abundance for these two species.

Another three species, American Robin, Chipping Sparrow, and Dark-eyed Junco, increased significantly at moderate-severity points only, providing further evidence that fire severity is important in explaining bird responses to fire. A strong response to a single severity suggests that one or more measures of habitat quality (e.g., food resources, nest site availability, cover from predators) differ with fire severity. These species may be taking advantage of a unique combination of resources that occurs after moderate-severity burns-increased food (insect and seed availability; Huff and Smith 2000, Short 2003) and the presence of live foliage to conceal nests. All three species are primarily ground and/or foliage gleaning insectivores, although Dark-eyed Junco and Chipping Sparrow also forage on seeds (Ehrlich et al. 1988). Some studies have also shown that, although these species are detected in many habitat types, they are often more abundant in burned than unburned forest types (Pfister 1980, Raphael and White 1984, Skinner 1989, Hutto 1995). Nonetheless, because most previous authors have either lumped data

Note: The statistical significance and associated direction of response to fire is noted only for species with $\geq 40$ detections, which are also highlighted in boldface.

$\dagger$ Twenty-one additional species were detected two times or less: Canada Goose (Branta canadensis), Cooper's Hawk (Accipiter cooperii), Northern Goshawk (Accipiter gentilis), American Kestrel (Falco sparverius), Common Snipe (Gallinago gallinago), Great Gray Owl (Strix nebulosa), Common Nighthawk (Chordeiles minor), Vaux's Swift (Chaetura vauxi), Whitethroated Swift (Aeronautes saxatalis), Belted Kingfisher (Ceryle alcyon), Lewis' Woodpecker (Melanerpes lewis), Cordilleran Flycatcher (Empidonax occidentalis), Black-billed Magpie (Pica pica), Tree Swallow (Tachycineta bicolor), Veery (Catharus fuscescens), Gray Catbird (Dumetella carolinensis), American Redstart (Setophaga ruticilla), Spotted Towhee (Pipilo maculatus), Brewer's Sparrow (Spizella breweri), Western Meadowlark (Sturnella neglecta), and Bullock's Oriole (Icterus bullockii).

† Before-fire years were 1994, 1995, 1996, 1998, 2000.

$\S$ After-fire years were 2001-2003.

$\|$ Response is noted only for species with $\geq 40$ detections and whose distributions meet normality assumptions. IE, insufficient evidence for a statistically significant difference in abundance from before to after fire; $\mathrm{D}$, decrease in relative abundance from before to after fire; I, increase in relative abundance from before to after fire. A significant difference between the amount of change at burned and unburned points is indicated as follows: $\#<0.1 ; * P<0.05$; ** $P<0.01$. $P$ values are derived from $F$ tests that use the type III sums-of-squares obtained from linear mixed models.

If Distributions for these species did not meet normality assumptions and so tests were not performed for these species. 
TABlE 4. Difference (after-fire mean minus before-fire mean, $\pm \mathrm{SE}$ ) in the number of birds detected within $100 \mathrm{~m}$ per point $(\times 100)$ at unburned points and at points that burned at low, moderate, or high severity.

\begin{tabular}{|c|c|c|c|}
\hline Species & Unburned $(n=120)$ & Low $(n=52)$ & Moderate $(n=32)$ \\
\hline Calliope Hummingbird & $3.2 \pm 1.8$ & $1.9 \pm 2.3$ & $4.2 \pm 2.8$ \\
\hline Northern Flicker & $-3.1 \pm 2.2$ & $-7.2 \pm 3.2$ & $6.5 \pm 4.1$ \\
\hline Williamson's Sapsucker§ & $-1.5 \pm 2.8$ & $-2.6 \pm 3.6$ & $-5.5 \pm 4.2$ \\
\hline Hairy Woodpecker & $4.2 \pm 2.6$ & $3.2 \pm 3.7$ & $11.9 \pm 4.4$ \\
\hline Olive-sided Flycatcher\| & $-1.3 \pm 2.0$ & $-3.5 \pm 2.8$ & $4.0 \pm 3.4$ \\
\hline Hammond's Flycatcher\$ & $10.5 \pm 3.7$ & $3.8 \pm 4.5$ & $4.8 \pm 5.0$ \\
\hline Dusky Flycatcher & $9.5 \pm 4.0$ & $9.1 \pm 5.1$ & $2.9 \pm 5.9$ \\
\hline Cassin's Vireo & $2.9 \pm 2.3$ & $-0.9 \pm 3.4$ & $-6.5 \pm 4.3$ \\
\hline Warbling Vireo & $2.3 \pm 4.1$ & $-2.8 \pm 5.6$ & $-9.4 \pm 6.8$ \\
\hline Clark’s Nutcracker & $-5.9 \pm 3.7$ & $-6.3 \pm 5.1$ & $-10.8 \pm 6.2$ \\
\hline Black-capped Chickadee & $1.0 \pm 2.4$ & $1.9 \pm 3.0$ & $5.5 \pm 3.5$ \\
\hline Mountain Chickadee & $29.7 \pm 9.3$ & $24.8 \pm 11.5$ & $15.5 \pm 13.0$ \\
\hline Brown Creeper & $3.1 \pm 2.4$ & $7.4 \pm 3.2$ & $7.2 \pm 3.8$ \\
\hline Red-breasted Nuthatch & $-1.8 \pm 7.4$ & $2.5 \pm 9.8$ & $3.0 \pm 11.5$ \\
\hline Winter Wren & $2.2 \pm 2.2$ & $0.0 \pm 2.9$ & $-4.0 \pm 3.4$ \\
\hline Golden-crowned Kinglet & $8.9 \pm 4.0$ & $-5.2 \pm 5.5$ & $-10.7 \pm 6.6$ \\
\hline Ruby-crowned Kinglet & $28.3 \pm 8.3$ & $8.0 \pm 10.0$ & $-7.7 \pm 11.1$ \\
\hline Mountain Bluebird & $-0.9 \pm 2.5$ & $-3.2 \pm 3.3$ & $5.6 \pm 3.9$ \\
\hline Townsend's Solitaire§ & $-9.0 \pm 3.4$ & $-6.9 \pm 4.8$ & $-3.2 \pm 5.8$ \\
\hline Swainson's Thrush & $6.2 \pm 3.6$ & $-1.9 \pm 4.9$ & $-5.2 \pm 5.9$ \\
\hline Hermit Thrush & $-3.4 \pm 3.4$ & $7.8 \pm 4.4$ & $-3.9 \pm 5.1$ \\
\hline American Robin§ & $0.6 \pm 5.9$ & $-13.5 \pm 7.6$ & $23.7 \pm 8.8$ \\
\hline Yellow-rumped Warbler§ & $28.4 \pm 7.5$ & $12.2 \pm 10.3$ & $-1.8 \pm 12.4$ \\
\hline Townsend's Warbler & $10.1 \pm 7.1$ & $11.2 \pm 8.7$ & $0.7 \pm 9.9$ \\
\hline MacGillivray's Warbler & $2.0 \pm 6.0$ & $-3.9 \pm 7.1$ & $-7.5 \pm 7.9$ \\
\hline Western Tanager§ & $2.4 \pm 5.2$ & $23.9 \pm 7.3$ & $12.1 \pm 8.9$ \\
\hline Chipping Sparrow§ & $19.5 \pm 9.3$ & $31.1 \pm 12.2$ & $68.2 \pm 14.3$ \\
\hline Dark-eyed Junco§ & $0.2 \pm 10.2$ & $31.4 \pm 14.1$ & $55.7 \pm \mathbf{1 7 . 0}$ \\
\hline Lazuli Buntingd & $9.6 \pm 7.5$ & $29.5 \pm 8.5$ & $35.9 \pm 9.2$ \\
\hline Brown-headed Cowbird & $-0.6 \pm 3.2$ & $-3.0 \pm 4.4$ & $4.0 \pm 5.3$ \\
\hline Cassin’s Finch§凹 & $-1.1 \pm 2.2$ & $5.5 \pm 3.0$ & $3.8 \pm 3.6$ \\
\hline Pine Siskin $§$ & $-7.6 \pm 13.2$ & $13.7 \pm 17.9$ & $39.3 \pm 21.3$ \\
\hline
\end{tabular}

Notes: Species include only those with $\geq 40$ detections and normal distributions. Any before-fire to after-fire difference that is significantly $(P \leq 0.05)$ greater than the difference recorded at unburned points is highlighted in bold; no adjustments were made for multiple comparisons. The "Time" column denotes the direction of change for those species in which there was a twofold difference in the mean relative abundance from one year after to two years after fire at one or more fire severities.

$\dagger$ The $F$ test of significance uses the type III sums-of-squares obtained from a linear mixed model.

\$ D, relative abundance decreased by half from 2001 to 2002; I, relative abundance doubled from 2001 to 2002; I/D, relative abundance increased in one severity and decreased in another from 2001 to 2002.

\$ Species previously classified by Kotliar et al. (2002) as mixed or neutral responders to fire.

\| Olive-sided Flycatchers were rarely detected within $100 \mathrm{~m}$ of the point; relative abundance estimates based on all detections within $400 \mathrm{~m}$ were as follows: unburned, $3.9 \pm 4.5$; low, $2.7 \pm 5.4$; moderate, $12.8 \pm 6.1$; high, $20.5 \pm 6.1 ; \mathrm{df}, 3,58.5 ; F$ $=2.8 ; P=0.048$.

II These species showed significant differences between burned and unburned points before breaking down relative abundance by fire severity (see Table 3 ).

across fire severity or have not been specific about which fire severity was studied, it has been difficult to determine whether these species respond uniformly to fire. For example, two studies found American Robin abundance to be relatively high in some but not in other burned plots (Pfister 1980, Harris 1982), while another study showed robins to be twice as abundant on all burned plots (Taylor and Barmore 1980). Similarly, Taylor and Barmore (1980) found the Chipping Sparrow to be most abundant in plots that burned at moderate severity, while Harris (1982) reported a greater abundance of this species in some burned replicates but not others, and Pfister (1980) reported that Chipping Sparrows were more abundant in unburned plots. Perhaps studies that find a "mixed response" among plots, or syntheses that conclude an overall response is mixed or "neutral," are simply detecting responses that differ depending on fire severity. Indeed, when we compared differences in relative abundance before and after fire without breaking fire down by severity, there were no significant differences in relative abundance between burned and unburned points for American Robin and Chipping Sparrow (Table 3).

Seven species (Cassin's Vireo, Dusky Flycatcher, Ruby-crowned Kinglet, Golden-crowned Kinglet, Swainson's Thrush, Yellow-rumped Warbler, and Townsend's Warbler) decreased in relative abundance after fire, and previous studies concur that five of these are typically more abundant in unburned forest (Kotliar et al. 2002). That many forest species decrease most 
TABLE 4. Extended.

\begin{tabular}{|c|c|c|c|c|}
\hline High $(n=38)$ & df & $F \dagger$ & $P$ & Time \\
\hline $1.8 \pm 2.6$ & $3,56.4$ & 0.2 & 0.87 & \\
\hline $8.4 \pm 3.8$ & $3,55.2$ & 4.9 & 0.004 & \\
\hline$-0.8 \pm 4.2$ & $3,56.9$ & 0.3 & 0.801 & \\
\hline $21.2 \pm 4.3$ & $3,55.1$ & 4.9 & 0.004 & I \\
\hline $0.4 \pm 3.3$ & $3,59.1$ & 1.2 & 0.321 & \\
\hline $4.8 \pm 5.1$ & $3,57.1$ & 0.5 & 0.694 & $\mathrm{D}$ \\
\hline$-7.9 \pm 5.9$ & $3,58.8$ & 2.6 & 0.06 & $\mathrm{D}$ \\
\hline$-8.2 \pm 4.0$ & $3,57.5$ & 2.5 & 0.068 & \\
\hline$-10.1 \pm 6.6$ & $3,58.2$ & 1.2 & 0.324 & \\
\hline$-1.5 \pm 6.0$ & $3,57.9$ & 0.5 & 0.718 & I \\
\hline $1.0 \pm 3.5$ & $3,49.4$ & 0.6 & 0.643 & \\
\hline$-2.9 \pm 13.1$ & $3,55.9$ & 1.7 & 0.185 & $\mathrm{D}$ \\
\hline $5.6 \pm 3.7$ & $3,58.8$ & 0.4 & 0.72 & I \\
\hline$-24.1 \pm 11.4$ & $3,57.9$ & 1.6 & 0.197 & \\
\hline$-1.7 \pm 3.3$ & $3,53.9$ & 0.9 & 0.466 & \\
\hline$-18.1 \pm 6.4$ & $3,52.2$ & 4.9 & 0.005 & $\mathrm{D}$ \\
\hline$-36.1 \pm 11.3$ & $3,59.3$ & 7.9 & $<0.001$ & $\mathrm{D}$ \\
\hline $18.2 \pm 3.8$ & $3,59.2$ & 8.3 & $<0.001$ & $\mathrm{I} / \mathrm{D}$ \\
\hline $15.6 \pm 5.6$ & $3,51.9$ & 5.0 & 0.004 & I \\
\hline$-13.4 \pm 5.8$ & $3,48.7$ & 2.9 & 0.045 & \\
\hline$-11.4 \pm 5.1$ & $3,59.6$ & 3.6 & 0.018 & \\
\hline $17.2 \pm 8.8$ & $3,58.6$ & 5.7 & 0.002 & I \\
\hline$-4.5 \pm 12.0$ & $3,57.9$ & 2.4 & 0.081 & \\
\hline$-15.3 \pm 10.0$ & $3,55.8$ & 2.2 & 0.10 & $\mathrm{D}$ \\
\hline$-4.4 \pm 8.1$ & $3,57.2$ & 0.3 & 0.822 & \\
\hline$-15.4 \pm 8.6$ & $3,57.2$ & 4.7 & 0.005 & \\
\hline $32.2 \pm 14.2$ & $3,59.9$ & 3.0 & 0.038 & \\
\hline $6.2 \pm 16.5$ & $3,57.3$ & 3.1 & 0.034 & \\
\hline $25.3 \pm 9.4$ & $3,57.8$ & 1.7 & 0.171 & I \\
\hline$-3.4 \pm 5.1$ & $3,56.4$ & 0.5 & 0.671 & \\
\hline $5.5 \pm 3.5$ & $3,57.0$ & 1.4 & 0.253 & $\mathrm{D}$ \\
\hline$-9.9 \pm 20.9$ & $3,60.1$ & 1.5 & 0.222 & \\
\hline
\end{tabular}

strongly in abundance after fire at the more severely burned points should not be surprising; all of these species build nests in the live foliage of trees and shrubs, and most are foliage gleaners (Ehrlich et al. 1988). What was unexpected was that, for four out of seven species (Cassin's Vireo, Dusky Flycatcher, Swainson's Thrush, and Townsend's Warbler), changes in relative abundance from before to after fire at moderate and low-severity points were not significantly different than changes at unburned points. This suggests that fire severity is important even to species that respond negatively to fire, and that fire effects may not be severe enough to affect abundance unless the fire burns at high severity.

Two species that decreased in response to fire (Rubycrowned Kinglet and Yellow-rumped Warbler) actually

TABLE 5. The number of transects (and points in parentheses) on which four uncommon species were detected before and after fire.

\begin{tabular}{lll}
\hline \hline \multicolumn{1}{c}{ Species } & Before & After \\
\hline American Three-toed Woodpecker & $1(1)$ & $6(11)$ \\
Black-backed Woodpecker & 0 & $2(3)$ \\
Western Wood-Pewee & 0 & $4(10)$ \\
House Wren & $2(3)$ & $4(13)$ \\
\hline
\end{tabular}

appeared to increase at points that did not burn or that burned at low severity (Table 4 and Fig. 2D). This may be due to local movements from burned to unburned or less severely burned forest, and this has important implications for how we design studies of fire effects. Specifically, studies in which burned habitat is compared with adjacent or nearby unburned habitat may be biased toward finding significant differences in bird abundance between the two forest types if birds are moving from burned to unburned areas. Few data are available to quantify this kind of movement, but in a study conducted in sagebrush habitat where one study plot burned, color-banded Brewer's Sparrows (Spizella breweri) shifted to the nearest patch of unburned shrubs (B. Walker, personal communication). In another example, Johnson and Wauer (1996) had an opportunity to examine changes in abundance from before to after fire and noted changes in abundance at unburned points after fire. In their study, woodpecker abundance increased at unburned points, and they hypothesized that this was due to an overflow from larger increases in woodpecker populations on burned transects in their study area. In this case, spillover of species that respond positively to fire from burned to adjacent unburned forest could create a bias against finding significant differences between the two forest types. Thus, 

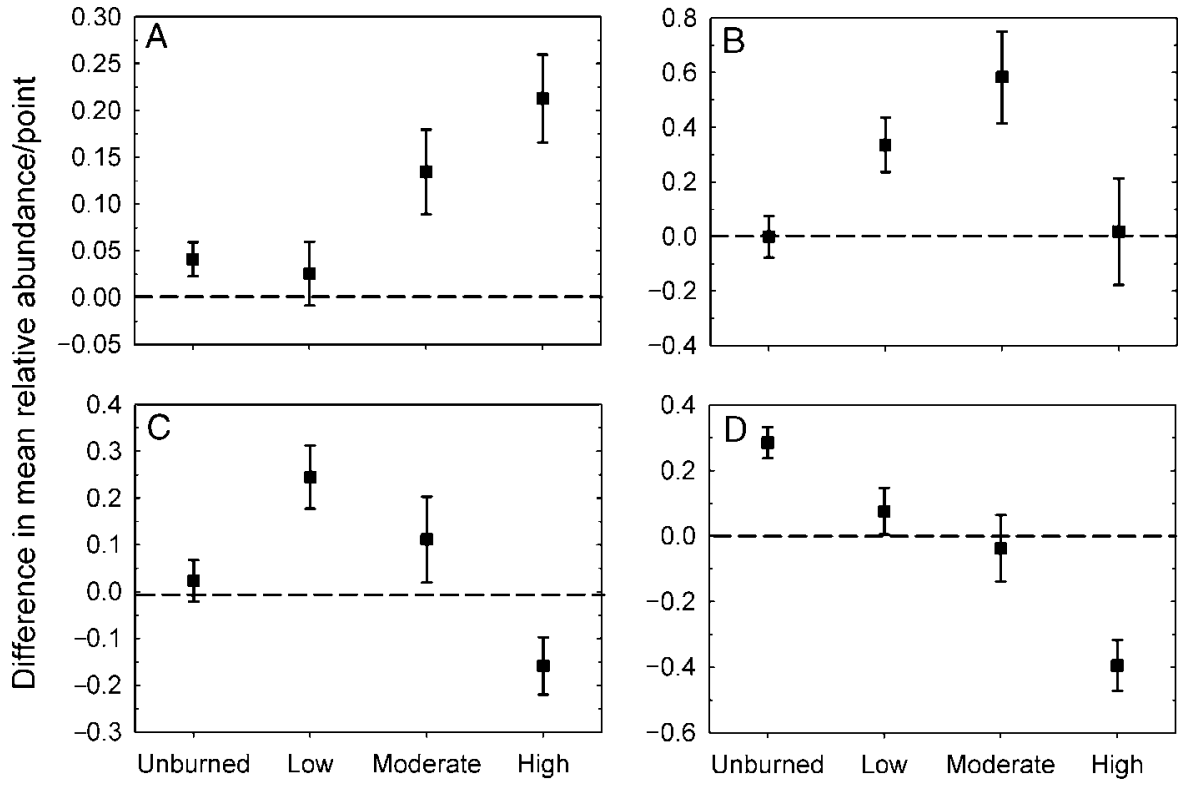

Fire severity

FIG. 2. Four common patterns (panels A-D) of change in bird abundance after fire. The pattern in (A) represents species whose abundance increased primarily in the more severely burned forest patches (exemplified here by data from Hairy Woodpecker). Pattern B represents species whose abundances increased primarily in moderately burned patches (exemplified here by data from Dark-eyed Junco). Pattern C represents species whose abundances increased primarily in the low-severity patches (exemplified here by data from Western Tanager). Pattern D represents species whose abundances tended to increase in unburned patches after fire while decreasing primarily in the more severely burned patches (exemplified here by data from Ruby-crowned Kinglet). Error bars represent \pm SE. See Results and Table 4 for examples of other species that fit each pattern.
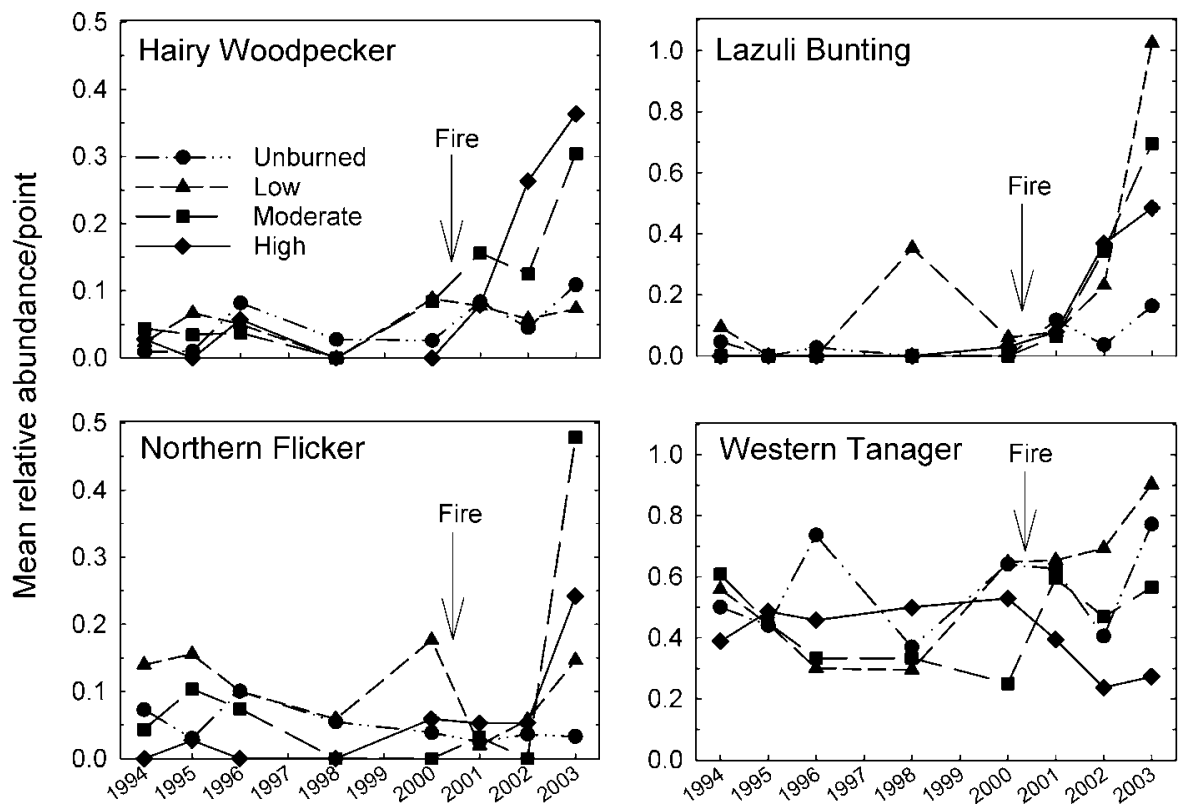

FIG. 3. Mean number of birds detected per point, broken down by both fire severity and year (1994-2003) for Hairy Woodpecker, Lazuli Bunting, Northern Flicker, and Western Tanager. 
local bird movement between burned and unburned forest has the potential to bias fire effects studies in either direction; further study is needed to determine how far these local movements might extend.

\section{The importance of time since fire}

Results from this study also suggest that a species' response to fire depends on the number of years since fire. For example, Northern Flicker showed no evidence of a fire response until the third year after fire (Fig. 3), so had we analyzed only the first two years of postfire data, we would have missed this positive response. In fact, many species that showed changes in relative abundance from before to after fire also showed substantial changes in relative abundance from one year after to two years after fire (Table 4). Further, the direction of these changes was almost always the sameincreasers showed greater increases in relative abundance and decreasers showed greater decreases in relative abundance two years after fire than one year after fire. Lazuli Bunting is perhaps the best example of this pattern (Fig. 3); this species increased in relative abundance fairly equally at all fire severities, and it continued to increase at all fire severities each year postfire. Several other researchers have suggested that this species might be more common on burned than unburned plots (Bock and Lynch 1970, Harris 1982, Raphael et al. 1987, Skinner 1989), but low sample sizes during early years after fire made it difficult for these authors to evaluate whether buntings respond positively to fire or not. In addition, our results suggest that it may take several years for a response to fire to become obvious for this species. Thus, studies that examine only the first year or two after fire may not detect a meaningful biological response.

Studies and syntheses of fire effects on wildlife often lump data across the first few years after wildfire to increase postfire sample size (e.g., postfire years 1-3 in this study; postfire years 1-6 in Kotliar et al. 2002). However, lumping data across the first few years after fire may hide important differences in relative abundance that occur only briefly after fire. For example, in our study, Cassin's Finch and Pine Siskin were more than twice as abundant one year after fire than two years after fire, suggesting that these species may respond to short-term increases in the availability of seeds after wildfire.

\section{Conclusions and management implications}

The BACI approach employed in this study, combined with our attention to fire severity and time since fire, revealed several patterns that were consistent for both vegetation and bird communities: (1) the magnitude of change from before to after fire increased as severity increased, (2) many vegetation layers and bird species experienced little change at any but the most severely burned points, and (3) coverage of many vegetation layers and relative abundances of many bird species changed from one year after to two years after fire. These observations highlight two issues that may have been a source of confusion in past studies. First, because different fire severities produce different kinds of postfire structure, bird responses also depend on fire severity. Thus, as emphasized by Whelan (1995), and more recently by Short (2003), studies that have not clearly defined or differentiated fire severities may obtain variable results on how birds respond to fire. Despite the importance of fire severity, we were able to find only one published study (Taylor and Barmore 1980) that examined bird abundance across more than one severity in conifer forests. Moreover, few published studies provide adequate fire descriptions to ensure that fire severity is similar within and among replicates, or to ensure that readers can decipher what kind of fire severity was studied. Our finding that for 10 species, fire effects become apparent only if fire severity is accounted for underscores the importance of considering fire severity when we study fire effects. The mixed response noted in the literature appears to result, at least in part, from differing responses to different kinds of fires, and not from variable responses to the same fire conditions. Further, our discovery of seven species that respond most strongly to a particular fire severity suggests that different severities offer unique conditions or combinations of resources.

Second, the potential for interaction between fire severity and time since fire makes the evaluation of fire effects complex. In our study, vegetation cover and relative abundance for many bird species differed depending on fire severity, time since fire, or both. This has important implications for how we analyze and interpret data from fire studies. Both pooling data from the first few years after fire and comparing studies conducted in burned forests that are different ages postfire may obscure important yearly changes in bird abundance. Intensive studies designed to evaluate how reproductive output, survival, and other measures of fitness differ across fire severity are needed to verify and understand mechanisms behind changes in bird abundance both between postfire years and among different fire severities.

The finding that different fire severities best meet the needs of different bird species has profound implications for how we study, manage, and perceive fire. When designing studies to examine bird abundance in burned and unburned forest, we need to be sure that replicates are homogeneous with respect to fire severity, or else abundance estimates may be confounded. In managing U.S. Forest Service lands, we cannot rely solely on "thin and burn" prescriptions for forest restoration because uniform, low-severity understory burns will not meet the needs of all species (see also Turner et al. 2003). Indeed, other researchers have noted that homogeneous burning regimes (Schurbon and Fauth 2003, 2004) will not provide suitable conditions for all amphibian species. Instead, we need to prescribe 
and allow for a range of fire severities, including so called "catastrophic" fires, if we want to meet the habitat needs of all species. This will be difficult in the face of the prevailing educational campaigns designed to convince the public that anything but low-severity understory fire is unnatural in low- to mid-elevation mixed-conifer forests. Although the proportion of fires that burn at high-severity varies with forest type (Schoennagel et al. 2004), many studies (Shinneman and Baker 1997, Brown et al. 1999, Baker and Ehle 2001, Ehle and Baker 2003, Fulé et al. 2004) suggest that even within low-elevation mixed-conifer forests dominated by ponderosa pine, high-severity fires are well within the range of natural variability. Indeed, our finding that several species respond strongly and positively to high-severity fire provides a second line of evidence that these types of fires provide suitable conditions within low-elevation mixed-conifer forests.

Our study also has important implications for how we interpret the effects of large, stand-replacing fires in forests that are typically thought to have a frequent, low-severity fire regime, such as those in the Bitterroot Valley. Stand-replacement fires are often perceived as destructive, homogenizing forces. In reality, high-severity fires, such as those that burned throughout Yellowstone National Park in 1988, tend to create heterogeneous landscapes made up of a mosaic of unburned patches and patches that burn at a wide range of fire severities (Turner et al. 2003). Similarly, in the summer of 2000, 20\% of the Bitterroot National Forest burned, but only $36 \%$ of this area burned at high severity, while the rest burned at lower severities (USDA Forest Service $2000 a$ ). The responses of bird species to the Bitterroot fires of 2000 were as diverse as the fires themselves, and depended on both fire severity and the number of years since fire. While some species were negatively affected by the highest fire severities, these same fires were a creative and restorative process for an even greater number of species that responded positively to the unique set of conditions created by mixedseverity wildfire.

\section{ACKNOWLEDGMENTS}

This research was funded by Region 1 of the U.S. Forest Service. We thank Skip Kowalski, who recognized this unique opportunity provided by NRLMP data collected in the Bitterroot National Forest and who helped secure funding for this research. We are grateful to the Bitterroot National Forest Staff, especially Dave Lockman and John Ormiston, for financial and logistic support. We thank the dozens of field technicians that helped collect data for this study, and we are especially grateful for the depth and breadth of comments offered by Amy Cilimburg, Rob Fletcher, and two anonymous reviewers.

\section{Literature Cited}

Agee, J. K. 1993. Fire ecology of Pacific Northwest forests. Island Press, Washington, D.C., USA.

Altman, B., and R. Sallabanks. 2000. Olive-sided Flycatcher (Contopus cooperi). In A. Poole and F. Gill, editors. The birds of North America, number 502. The Birds of North America, Philadelphia, Pennsylvania, USA.
Andersen, A. N., R. W. Braithwaite, G. D. Cook, L. K. Corbett, R. J. Williams, M. M. Douglas, A. M. Gill, S. A. Setterfield, and W. J. Muller. 1998. Fire research for conservation management in tropical savannas: introducing the Kapalga fire experiment. Australian Journal of Ecology 23: 95-110.

Arno, S. F., and S. Allison-Bunnel. 2002. Flames in our forest: disaster or renewal? Island Press, Washington D.C., USA.

Baker, W. L., and D. Ehle. 2001. Uncertainty in surface-fire history: the case of ponderosa pine forests in the western United States. Canadian Journal of Forest Research 31: 1205-1226.

Bock, C. E., and J. H. Bock. 1983. Responses of birds and deer mice to prescribed burning in ponderosa pine. Journal of Wildlife Management 47:836-840.

Bock, C. E., and J. F. Lynch. 1970. Breeding bird populations of burned and unburned conifer forest in the Sierra Nevada. Condor 72:182-189.

Brawn, J. D., S. K. Robinson, and F. R. Thompson, III. 2001. The role of disturbance in the ecology and conservation of birds. Annual Review of Ecology and Systematics 32:251276.

Brown, J. K., and J. K. Smith. 2000. Wildland fire in ecosystems: effects of fire on flora. USDA Forest Service General Technical Report RMRS-GTR-42. Volume 2. Rocky Mountain Research Station, Ogden, Utah, USA.

Brown, P. M., M. R. Kaufmann, and W. D. Shepperd. 1999. Long-term, landscape patterns of past fire events in a montane ponderosa pine forest of central Colorado. Landscape Ecology 14:513-532.

Caton, E. L. 1996. Effects of fire and salvage logging on the cavity-nesting bird community in northwestern Montana. Dissertation. University of Montana, Missoula, Montana, USA.

Ehle, D. S., and W. L. Baker. 2003. Disturbance and stand dynamics in ponderosa pine forests in Rocky Mountain National Park, USA. Ecological Monographs 73:543-566.

Ehrlich, P. R., D. S. Dobkin, and D. Wheye. 1988. The birder's handbook. Simon and Schuster, New York, New York, USA.

Fulé, P. Z., A. E. Cocke, T. A. Heinlein, and W. W. Covington. 2004. Effects of an intense prescribed forest fire: is it ecological restoration? Restoration Ecology 12:220-230.

Granholm, S. 1982. Effects of surface fires on birds and their habitat associations in coniferous forests of the Sierra Nevada, California. Thesis. University of California, Davis, California, USA.

Habeck, J. R., and R. W. Mutch. 1973. Fire-dependent forests in the northern Rocky Mountains. Journal of Quaternary Research 3:408-424.

Hargrove, W. W., and J. Pickering. 1992. Pseudoreplication: a sine qua non for regional ecology. Landscape Ecology 6:251-258.

Harris, M. A. 1982. Habitat use among woodpeckers in forest burns. Thesis. University of Montana, Missoula, Montana, USA.

Hoyt, J. S., and S. J. Hannon. 2002. Habitat associations of Black-backed and Three-toed woodpeckers in the boreal forest of Alberta. Canadian Journal of Forest Research 32: $1881-1888$.

Huff, M. H., and J. K. Smith. 2000. Fire effects on animal communities. Pages 35-42 in J. K. Smith, editor. Wildland fire in ecosystems: effects of fire on fauna. USDA Forest Service, Rocky Mountain Research Station, Ogden, Utah, USA.

Hutto, R. L. 1995. Composition of bird communities following stand-replacement fires in northern Rocky Mountain (U.S.A.) conifer forests. Conservation Biology 9:10411058 . 
Hutto, R. L., S. M. Pletschet, and P. Hendricks. 1986. A fixedradius point count method for nonbreeding and breeding use. Auk 103:593-602.

Hutto, R. L., and J. S. Young. 1999. Habitat relationships of landbirds in the Northern Region. USDA Forest Service General Technical Report RMRS-GTR-32.

James, F. C., and C. E. McCulloch. 1995. The strength of inferences about causes of trends in populations. Pages 4051 in T. E. Martin and D. M. Finch, editors. Ecology and management of neotropical migratory birds. Oxford University Press, New York, New York, USA.

Johnson, T., and R. Wauer. 1996. Avifaunal response to the 1977 La Mesa fire. Pages 70-94 in C. Allen, editor. Fire effects in Southwestern forests: proceedings of the second La Mesa Fire Symposium. USDA Forest Service Rocky Mountain Forest and Range Experiment Station, Los Alamos, New Mexico, USA.

Kotliar, N. B., S. J. Heijl, R. L. Hutto, V. A. Saab, C. P. Melcher, and M. McFadzen. 2002. Effects of fire and postfire salvage logging on avian communities in conifer-dominated forests of the western United States. Studies in Avian Biology 25:49-64.

Murphy, E. G., and W. H. Lehnhausen. 1998. Density and foraging ecology of woodpeckers following a stand-replacement fire. Journal of Wildlife Management 62:13591372.

Pfister, A. 1980. Postfire avian ecology in Yellowstone National Park. Thesis. Washington State University, Pullman, Washington, USA.

Platt, W. J., and J. H. Connell. 2003. Natural disturbances and directional replacement of species. Ecological Monographs 73:507-522.

Ralph, C. J., J. R. Sauer, and S. Droege. 1995. Monitoring bird populations by point count. USDA Forest Service General Technical Report PSW-149.

Raphael, M. G., M. L. Morrison, and M. P. Yoder-Williams. 1987. Breeding bird populations during twenty-five years of postfire succession in the Sierra Nevada. Condor 89: 614-626.

Raphael, M. G., and M. White. 1984. Use of snags by cavitynesting birds in the Sierra Nevada. Wildlife Monographs 84:1-66.

Saab, V. A., and J. G. Dudley. 1998. Responses of cavitynesting birds to stand-replacement fire and salvage logging in ponderosa pine/Douglas-fir forests of southwestern Idaho. USDA Forest Service Research Paper RMRS-RP 11: $1-17$.

Schoennagel, T., T. T. Veblen, and W. H. Romme. 2004. The interaction of fire, fuels, and climate across Rocky Mountain forests. BioScience 54:661-676.

Schulte, L. A., and G. J. Niemi. 1998. Bird communities of early-successional burned and logged forest. Journal of Wildlife Management 62:1418-1429.

Schurbon, J. M., and J. E. Fauth. 2003. Effects of prescribed burning on amphibian diversity in a southeastern U.S. national forest. Conservation Biology 17:1338-1349.
Schurbon, J. M., and J. E. Fauth. 2004. Fire as friend and foe of amphibians: a reply. Conservation Biology 18:11561159.

Shinneman, D. J., and W. L. Baker. 1997. Nonequilibrium dynamics between catastrophic disturbances and oldgrowth forests in ponderosa pine landscapes of the Black Hills. Conservation Biology 11:1276-1288.

Short, K. C. 2003. Complexity and variation in the effects of low-severity fires on forest biota. Dissertation. University of Montana, Missoula, Montana.

Skinner, N. G. 1989. Seasonal avifauna use of burned and unburned lodgepole pine forest ecotones. Thesis. University of Montana, Missoula, Montana, USA.

Smith, J. K. 2000. Wildland fire in ecosystems: effects of fire on fauna. USDA Forest Service General Technical Report RMRS-GTR-42. Volume 1. Rocky Mountain Research Station, Ogden, Utah, USA

Smucker, K. M. 2003. Changes in bird abundance and species composition in a coniferous forest following a mixed-severity wildfire. Thesis. University of Montana, Missoula, Montana, USA.

SPSS. 2002. SPSS for Windows, release 11.5.0. SPSS, Chicago, Illinois, USA.

Steele, B. M., and J. T. Hogg. 2003. Measuring individual quality in conservation and behaviour studies. Pages 243268 in M. Festa-Bianchet and M. Apollonio, editors. Animal behaviour and wildlife conservation. Island Press, Washington, D.C., USA.

Stewart-Oaten, A., W. W. Murdoch, and K. R. Parker. 1986. Environmental impact assessment: "pseudoreplication" in time? Ecology 67:929-940.

Taylor, D. L., and W. J. Barmore. 1980. Post-fire succession of avifauna in coniferous forests of Yellowstone and Grand Teton National Parks, Wyoming. Pages 130-140 in R. M. DeGraff, editor. Workshop Proceedings: Management of western forests and grasslands for nongame birds. USDA Forest Service, Ogden, Utah, USA.

Turner, M. G., and V. H. Dale. 1998. Comparing large, infrequent disturbances: what have we learned? Ecosystems 1:493-496.

Turner, M. G., W. H. Romme, and D. B. Tinker. 2003. Surprises and lessons from the 1988 Yellowstone fires. Frontiers in Ecology and the Environment 1:351-358.

USDA Forest Service. 2000a. Bitterroot fires 2000: an overview of the events, effects on people and resources, and post-fire recovery priorities. Bitterroot National Forest, Hamilton, Montana, USA.

USDA Forest Service. 2000b. An assessment of post-fire conditions with recovery recommendations. Bitterroot National Forest, Hamilton, Montana, USA.

van Mantgem, P., M. Schwartz, and M. B. Keifer. 2001. Monitoring fire effects for managed burns and wildfires: coming to terms with pseudoreplication. Natural Areas Journal 21: 266-273.

Whelan, R. J. 1995. The ecology of fire. Cambridge University Press, Cambridge, UK. 